\title{
Planes modernizadores en el espacio andino del Departamento de Arica y el paradigma del desarrollo en la década de 1960*
}

\section{Modernizing plans in the Andean area of the Department of Arica and the paradigm of development in the 1960s}

\author{
Rodrigo Ruz Zagal* \\ Marisol Palma Behnke**
}

\section{RESUMEN}

El artículo muestra el inicial rol planificador de la Junta de Adelanto de Arica [JAA] con miras a la implementación de un proyecto de modernización capitalista dirigido hacia el desarrollo de las comunidades andinas rurales de la región fronteriza ariqueña a partir de la segunda mitad del siglo XX. Se establece una cronología respecto de las iniciativas desarrollistas y su progresivo deterioro, que culminaron con la ejecución de inversiones sectoriales que disgregaron la intención planificadora original. Se sugiere que este proyecto sucumbió ante aspectos idiosincráticos regionales propios de las comunidades andinas en su interacción con estructuras de desarrollo y la errática implementación de estas estrategias.

Palabras clave: Desarrollo, comunidades andinas, planificación, modernización, población indígena.

\section{ABSTRACT}

The article shows the initial planning role of the Junta de Adelanto de Arica [JAA] with a view to the implementation of a capitalist modernization project aimed at the development of rural Andean communities in the Arica border region from the second half of the century XX. A chronology is established regarding the development initiatives and their progressive deterioration, which culminated in the execution of sectorial investments that disintegrated the original planning intention. It is suggested that this project succumbed to idiosyncratic regional aspects typical of the Andean communities in their interaction with development structures and the erratic implementation of these strategies.

Keywords: Developing, Andean communities, planning, modernization, indigenous people.

Recibido: febrero 2021

Aceptado: mayo 2021

\footnotetext{
* Este artículo constituye un avance parcial del proyecto FONDECYT № 1181290 y Proyecto Mayor de Investigación Científica y Tecnológica UTA 5775-19.

* Dr. en Antropología por la Universidad de Tarapacá-Universidad Católica del Norte. Académico del Departamento de Ciencias Históricas y Geográficas, Universidad de Tarapacá, Chile. ORCID: https://orcid.org/0000-0002-74746441. Correo electrónico: rruz@uta.cl.

** Dra. en Historia por la Universidad de Leipzig. Académica del Departamento de Historia, Universidad Alberto Hurtado, Chile. ORCID: https://orcid.org/0000-0002-7497-2617.Correo electrónico:mpalmab@uahurtado.cl
} 


\section{Introducción}

La reconocida "área centro sur andina" de Latinoamérica (o Andes Centrales), a lo largo de su desarrollo histórico ha atravesado por diversos "proyectos" sociopolíticos y económicos que la insertan dentro de un proceso global. De este modo, a partir de la invasión europea, el desarrollo de estados nacionales con sus consecuentes pugnas modernas por su definición territorial y su incorporación al mercado mundial, estuvieron y están conectadas con procesos mundiales. Así, las diversas relaciones de poder fueron capaces de producir estrategias de control que definieron su dinámica y desarrollo en función de proyectos mayores.

Los fenómenos de modernización y modernidad en los Andes Centrales resultan particularmente interesantes en el contexto de desarrollos semejantes en el Cono Sur Americano, pues se trata, de un espacio en el que se pusieron en tensión los modos de vida tradicionales (indígenas) vis-à-vis los diversos proyectos antes señalados.

Para el caso puntual del espacio andino chileno, este fenómeno pudo observarse claramente finalizado el siglo XIX, en el contexto de la post Guerra del Pacífico que enfrentó a Chile con Perú y Bolivia, y que significó particularmente para Chile, la incorporación al territorio, soberanía y cultura del componente indígena quechua y aymara principalmente, grupos humanos que a fines del siglo XIX eran desconocidos en el imaginario nacional país.

Corrido el siglo XX, Chile como unidad política soberana, si bien ya estaba incorporada en el sistema-mundo capitalista $^{1}$, no podría decirse lo mismo de determinadas poblaciones/comunidades indígenas tanto con respecto al mismo Estado chileno como con los procesos vinculados con dicho sistema, el cual comenzó a hacerse patente a partir de la fase de expansión económico-mundial post 1945, bajo hegemonía estadounidense ${ }^{2}$. Este aspecto es relevante en cuanto obliga a comprender que la dinámica de la modernización latinoamericana, y chilena en particular, fue una continuación de los modelos y parámetros político-económicos eminentemente coloniales (o colonizadores), bajo una perspectiva que supone una difusión de

\footnotetext{
${ }^{1}$ Sobre el proceso de incorporación al sistema-mundo capitalista véase la siguiente bibliografía: Albert Bergesen, 1980. "Cycles of Formal Colonial Rule". En Hopkins, Terence K. y Wallerstein, I (Editores). Processes of the WorldSystem, Beverly Hills, Sage, pp. 119-126; Christopher Chase-Dunn and Thomas Hall, 1997. Rise and Demise: Comparing World-Systems, Nueva York, Westview Press.

${ }^{2}$ Sobre las ondas largas de desarrollo capitalista a escala mundial, desde 1945 en adelante, puede verse lo siguiente: Ernest Mandel, 1986[1980]. Las ondas largas del desarrollo capitalista. La interpretación marxista. Siglo XXI editores, España; Samir Amin et al,1983[1982]. Dinámica de la crisis global, Ciudad de México, Siglo XXI Editores, Immanuel Wallerstein, 1984." Long Waves as Capitalist Process" en Review, Vol. VII, N 4, Binghamton, pp. 559-575; Giovanni Arrighi, 2014[1994]. El largo siglo XX: Dinero y poder en los orígenes de nuestro tiempo, Akal ediciones, España; Robert Brenner, 2009[1998]. La economía de la turbulencia global, Madrid, Akal ediciones; Carlota Pérez, 2005[2003]. Revoluciones tecnológicas y capital financiero. La dinámica de las grandes burbujas financieras y las épocas de bonanza, Ciudad de México; Siglo XXI Editores, Andrew Glyn, 2012[2007]. Capitalismo desatado: finanzas, globalización y bienestar, Madrid, Los libros de la catarata.
} 
sus logros y adelantos en concordancia con las élites económico-políticas, así como de otras agencias a espaldas de la población indígena. Podría decirse que aquí se observa un proceso de "incorporación tardía" en el que ciertos reductos indígenas dejan de ser un área externa para pasar a ser agentes activos en las redes de producción e intercambio del sistema-mundo capitalista.

Como se ha indicado, la región de Arica adquirió importancia histórica al momento de su incorporación a la soberanía chilena Post Guerra del Pacífico, su situación trifronteriza y con problemáticas diplomáticas pendientes, transformó a una región relativamente marginal en el foco de atención nacional chilena y peruana e internacional ${ }^{3}$.

Luego de resueltos los conflictos limítrofes sostenidos entre Chile y Perú en 1929, y estar bajo plena soberanía chilena, la región de Arica vivió un período de relativo abandono entre las décadas de 1930-1950, el cuál sufrió un abrupto cambio entrada la década de 1950, a partir de medidas económicas excepcionales.

\section{La irrupción de los proyectos modernizadores a partir del establecimiento del Puerto Libre y Junta de Adelanto de Arica, 1950-1958.}

La situación post segunda guerra mundial, a nivel global y particularmente en países dentro de la órbita de influencia estadounidense en América Latina, impulsó la implementación de modelos económicos al alero del concepto de desarrollo autosostenido, que proyectaba la fórmula que una potencial industrialización tendría efectos multiplicadores y acumulativos sobre la sociedad en general, llevando así a un país (o a una región) en progresión geométrica hacia el desarrollo; ideas e ideología que progresivamente fueron madurando al alero de intelectuales economistas que influyeron en la política y economía global ${ }^{4}$. En lo teórico y fundamental, se proponía romper el círculo de la pobreza a través de un conjunto de medidas que posibilitarían pasar desde la etapa de una sociedad tradicional a una sociedad del consumo masivo. Para ello era menester introducir un impulso exterior que, en el caso del Departamento de Arica, sería dado por el Estado mediante el dictado de medidas excepcionales ${ }^{5}$. Bajo este

\footnotetext{
3 Si bien Arica "urbano" tuvo previo a la guerra altibajos en cuanto inversión estatal y consecuente desarrollo emanado por el entonces soberano Estado peruano que otorgó infraestructura urbana a la ciudad apelando a la proyección comercial adquirida por Arica como ciudad-puerto; este se vio truncado con los importantes eventos telúricos (terremoto y maremoto de 1868) que marcaron un decaimiento progresivo de la ciudad y su pulso, amplificado posteriormente por el maremoto y terremoto de 1877 y luego la guerra de 1879; contexto que enmarcó a la ciudad y su entorno a finales del siglo XIX. Una visión en detalle del "Arica peruano" puede ser encontrada en Díaz, Alberto, Ruz, Rodrigo, Galdames, Luis y Tapia Alejandro "El Arica peruano de ayer. Siglo XIX", Atenea, 159-184, Número 505, 2012, pp 159-184.

${ }^{4}$ Gunnar Myrdal, 1953. The Political Element in the Development of Economic Theory, Londres, Routledge \& Kegan Paul; Gunnar Myrdal, 1957. Economic Theory and Underdeveloped Regions, Londres, Gerald Duckworth \& Co; W. W. Rostow, 1961. Las etapas del crecimiento económico. Un manifiesto no-comunista, Ciudad de México, Fondo de Cultura Económica.

${ }^{5}$ Galdames, Luis, Notas epistemológicas sobre la teoría de la dependencia, Santiago, ILADES, 1978.
} 
influjo y tempranamente iniciada la década de 1950, durante el segundo gobierno del presidente Carlos Ibáñez del Campo (1952-58), se impulsa la creación de instrumentos de fomento al desarrollo económico. En el mes de julio de 1953 se promulgó el primero de ellos, el Decreto con Fuerza de Ley 303, que implementó bajo el nombre de Puerto Libre, políticas de liberación de aranceles e impuestos de aduana e industria que sugerían que el Departamento de Arica se transformara en un polo que atrajese inversores y compradores desde el resto del país, con el incentivo de adquirir en ella productos extranjeros a costo razonable, así como a su vez, desarrollar y promover el efecto amplificador que trae consigo la industrialización de una región en su entorno. No está del todo claro ni evaluado, que estas medidas diseñadas inicialmente tuviesen el éxito augurado, no obstante, en el período se generó una agitada e innegable actividad comercial y una incipiente industrialización ${ }^{6}$.

Un segundo momento de aplicación de medidas excepcionales para el logro del desarrollo económico del departamento, se dio con la promulgación del 15 de octubre de 1958 de la Ley 13.039 que definió la creación de un organismo de derecho público, autónomo y descentralizado, que administraría y canalizaría los recursos provenientes del régimen de Puerto Libre de que gozaba el Departamento de Arica desde el año 1953. Este organismo fue conocido y denominado la Junta de Adelanto de Arica [JAA].

Según el marco legal de la JAA, esta debería velar por el fomento de la producción, progreso y desarrollo del conjunto del Departamento de Arica. Esto bajo una óptica desarrollista en donde el adelanto y desarrollo se lograría: "con el mayor aprovechamiento y prospección de todas las riquezas naturales de la zona y la planificación de sus usos" ${ }^{\prime 7}$. Entre los objetivos fundantes de la JAA, se consideraba como pilar el: "adelanto rural y urbano del Departamento; para el fomento de sus fuentes de producción; para el incremento de su comercio y para el bienestar de sus habitantes, además de preocuparse de la buena conservación y funcionamiento de las obras realizadas, proveyendo a su permanente cuidado y reparación" ${ }^{8}$, aspectos que dirigieron su quehacer hasta el año de su derogación en 1976.

La JAA poseía una particular organización, sustentada en una estructura orgánica administrativa de corte gerencial, asesorada por un consejo compuesto por representantes de sectores activos de la comunidad; un grupo de componentes designados, liderados por el gobernador de la provincia, alcalde de la municipalidad, administrador del Ferrocarril de Arica a La Paz y el administrador de la Empresa Portuaria de Arica; así como componentes electos,

\footnotetext{
6 Pizarro, Elías y Ríos, Waldo. 2005. "Entre franquicias y beneficios: una apuesta del gobierno para el desarrollo regional de Arica (1953)", en Diálogo Andino, Número 25, Arica, pp. 101-111; Horacio Torrent y Rodrigo Ruz, "Proyectos para el desarrollo de Arica y su región en los años sesenta: El turismo en el laboratorio de los polos de crecimiento y la identidad del espacio andino", Diálogo andino, en prensa.

${ }^{7}$ Ley 13.039

8 Ídem.
} 
representantes de los sectores correspondientes a la agricultura, minería, empleados particulares, educación, Asociación de Industriales de Arica, Cámara de Comercio y Asociación de Pequeños Industriales de Arica.

Con la participación de un sector local conocedor del pulso regional y con un enfoque productivo, se buscó administrar los recursos económicos departamentales para mejorar las condiciones de la ciudad. En su ejercicio y en el ámbito productivo, la JAA promovió el establecimiento de industrias, continuando y promoviendo las bondades ariqueñas en el ámbito del consumo y comercio minorista y mayorista, así como su posicionamiento como producto turístico, mirando la potencial proyección internacional. Es conocido y estudiado el importante avance en materia de infraestructura y equipamiento urbano de la ciudad que fuese acorde a su sostenido crecimiento poblacional observado a partir de 1950.

La concepción de desarrollo al Departamento de Arica de la JAA no excluía a los sectores rurales; espacio, población y cultura que a la década de 1950 se encontraba muy poco asimilada a la vida citadina, sosteniendo un modo de vida apegado a la tradición vernacular asentado en sostener la vida en torno a los pueblos centrales desplegados en los sectores de valles bajos, precordillera y altiplano regional.

Si bien es conocido que la población indígena regional, históricamente ha sostenido vínculos económicos, políticos y culturales con los espacios urbanos de la región, estos en el período posterior a la década de 1950 se agudizarían, viéndose las comunidades andinas insertas dentro de programas de desarrollo de rural, estrategias que adquieren un tenor de carácter sectorial iniciada la JAA, tornándose más sistemático y ajustado a políticas estructuradas hacia la década de 1960, programas que en su conjunto vinieron a modificar los modos de vivir de la sociedad andina.

\section{De la inversión sectorial a la planificación fallida en la modernización de las comunidades andinas del Departamento de Arica, 1950-1968}

Tempranamente y a un año de su creación, la JAA inició estrategias para asumir el desafío de incorporar en la dimensión de desarrollo a los sectores rurales del Departamento de Arica. Con esto se hizo visible una realidad históricamente ausente en la política económica regional, como lo es la consideración de problemáticas productivas y económicas propias del mundo indígena, preferentemente Aymara. Cabe reconocer que estos grupos humanos hasta entrado el siglo XX eran prácticamente desconocidos para el imaginario nacional chileno, el que había sido construido sobre la base de un enfoque centralista, en donde la identidad nacional había sido erigida considerando aspectos culturales, societales y territoriales propios del Chile metropolitano y sureño, mas no nortino.

En la región, el trato o nexos establecidos entre las comunidades andinas y las estructuras estatales chilenas hacia las primeras décadas del siglo XX, venían más o menos establecidas por 
el proceso que siguió a la incorporación a la soberanía chilena de los territorios del nuevo norte chileno post Guerra del Pacífico (1879-1883), que en la región, por asuntos pendientes en materia diplomática, se extendió hasta $1929^{9}$.

Las comunidades andinas iniciado el siglo XX y hasta la mitad de este, se caracterizaban por ser comunidades históricas territorialmente definidas, con un tono de vida pueblerino y productivamente marcadas por procesos tradicionales agroganaderos desplegados en valles, precordillera y el altiplano regional. En estas, la presencia del Estado chileno radicaba en el otorgamiento de servicios precarios de salud y educación, con una relativa alta presencia de agentes estatales encargados de otorgar soberanía nacional chilena en el territorio. Parte de esta administración era otorgada por delegación a actores sociales y personajes notables de las comunidades, quienes realizaban acciones de administración del Estado con una orientación comunitaria y en pro del bien común.

Los aspectos productivos, se remitían a la producción agrícola tradicional: hortícola y frutícola en valles; maíz, orégano y papas preferentemente en precordillera; mientras que en el altiplano la economía tradicional era sustentada por la crianza de ganado auquénido (llamas y alpacas); en precordillera la ganadería era representada mayormente por crianza de ganado ovino y bovino. Las economías locales estaban conectadas marginalmente a centros urbanos costeros, proveyendo principalmente de productos bajo mecanismos comerciales (venta al menudeo) y tratos semicomerciales (trueque o intercambio de productos). Las economías campesinas, eran preferentemente enfocadas al autoconsumo, existiendo poca capacidad de capitalización. ${ }^{10}$

Las políticas de excepción establecidas por el Estado chileno a partir de la década de 1950 antes señaladas (DFL 303), propiciaron los primeros cambios en las estructuras tradicionales andinas. Arica pasó a ser un foco de atracción urbana que incentivaba el desarrollo en función del robustecimiento de la actividad comercial e industrial, esto impulsó la migración de los poblados andinos a la ciudad, acción que permitió que las personas adquirieran experiencia migratoria y urbana, alterando sus tradicionales modos de vida, estableciendo a su vez el proceso migratorio como un "problema" para el sostenimiento de las economías tradicionales y por ende, afectando al desarrollo de los espacios interiores del departamento.

\footnotetext{
${ }^{9}$ Debido al litigio diplomático pendiente legado por el Tratado de Ancón, que había definido que pasados 10 años de firmado el Tratado de Paz entre Chile y Perú, por medio de un plebiscito serían las comunidades de las ciudades fronterizas de Tacna y Arica, quienes decidirían su pertenencia nacional, chilena o peruana. Como es sabido dicho tratado establecido para el año 1929, no se realizó habiéndose zanjado la disputa por medio de la intervención internacional estadounidense en un acto que definió la pertenencia de la ciudad peruana de Tacna al Perú y de aquel entonces también ciudad peruana de Arica a Chile, véase Sergio González, La llave y el candado. El conflicto entre Chile y Perú por Tacna y Arica (1883-1929), Santiago, Lom Ediciones, 2008.

10 Héctor González, Hans Gundermann e Hidalgo, Jorge. 2014. "Comunidad indígena y construcción histórica del espacio entre los aymara del norte de Chile", en Chungara: Revista de antropología chilena, Vol. 46, Número 2, Arica, pp. 233-246.
} 
En este contexto se hacen visibles modificaciones importantes en las estructuras tradicionales de la vida, insertándose dentro de un creciente mercado y comercialización, adquiriendo a su tiempo bienes industriales y otorgando valoración de servicios urbanos. ${ }^{11}$

Ya implementada la JAA, el año 1959 se inicia una serie de medidas conducentes a establecer Planes de Desarrollo del Interior en el Departamento de Arica con el objetivo de incrementar el desarrollo agrícola y ganadero de la zona, atendiendo aspectos relacionados a la producción tradicional de los comuneros aymaras. Esto, buscado otorgar una raigambre territorial en los espacios rurales por parte de su población nativa.

El primer plan de desarrollo definido por la JAA con alcance genérico para la situación de los pueblos andinos del Departamento fue el Plan Desarrollo Agropecuario (1961-1967). Este integró aspectos estratégicos para la mejora de condiciones productivas, comerciales y en las condiciones de vida general para las comunidades andinas. Los diagnósticos desarrollados previos al plan identificaban aspectos negativos presentes en las comunidades tradicionales que entorpecerían su desarrollo. Estas estaban dadas por:

“a) El aprovechamiento parcial, muy bajo del recurso agua, b) Ineficiencia de la empresa agrícola, vale decir mal uso de los factores de producción (agua, suelos, fertilizantes, obra de mano, etc.) lo que incide en altos costos, c) La comercialización ineficiente y desaprovechamiento de mercados potenciales con ausentismo empresarial exageradamente alto, y d) la competencia de la producción hortalicera de Tacna". ${ }^{12}$

Para enfrentar este escenario negativo, el Plan de Desarrollo Agropecuario se planteó como objetivos: "Mejorar el aprovechamiento de los recursos agrícolas, particularmente del agua de riego; Mejorar la eficiencia de la empresa agrícola; Mejorar la comercialización de los productos agrícolas y mejorar las condiciones de vida de la población rural". ${ }^{13}$

Este plan, fue el resultado de un convenio entre la JAA y el Ministerio de Agricultura, en coordinación con la Corporación de Fomento, Dirección de Riego y la Caja de Colonización Agrícola; instancias que paralelamente desplegaban sectorialmente esfuerzos bajo el mismo espíritu desarrollista.

El programa, estableció una fuerte inversión en: reconocimiento de suelos, estudios químicos sobre afluentes de riego, mejoras de mercadeo, producción de frutales, mejora de semillas, campañas ganadero-sanitarias, estaciones de monta ganadera, obras de riego, recarga

\footnotetext{
11 Ídem.

12 Archivo Histórico Vicente Dagnino [ en adelante AHVD]. Informe Esquema de Planificación del Desarrollo Agropecuario de Arica. 1962. Estudios Técnicos JAA.

13 Ídem.
} 
de napas subterráneas, establecimiento de lecherías y establecimiento de administración cooperativa de los espacios agrícolas. ${ }^{14}$

Un año antes del Plan de Desarrollo del Interior (1960-1965), con un foco más específico se había establecido el "Plan Auquénido", que operó bajo la premisa de optimizar y mejorar la actividad ganadera tradicional altiplánica. Esto, a través de transformación de los procesos tradicionales de crianza, pastoreo, procesamiento y comercialización de los productos ganaderos. De acuerdo con el plan, se esperaba transformar la ganadería del altiplano, considerada "rudimentaria" y desaprovechada, persiguiendo objetivos que permitieran:

"1. Aumento de la masa ganadera existente actualmente en el altiplano, en un plazo de 10 años; 2 . Duplicar la actual producción de lana por animal; 3 . mejoramiento de la lana en sus aspectos de finura, uniformidad, elasticidad, etc.; 4. Fijación del tipo zootécnico de las distintas especies y variedades de auquénidos, a fin de abrir un registro genealógico; 5 . Aprovechamiento industrial en la zona de la lana, cuero y carne de estos animales; 6. Investigación científica sobre problemas biológicos y ecológicos de los auquénidos que hoy se desconocen totalmente; 7. Introducción de nuevas especies zoológicas en el altiplano con fines industriales como las ovejas "karakules", conejo angora y mejor aprovechamiento de la chinchilla y la vicuña; 8. Experiencias forrajeras con el fin de adaptar semillas de altura y llegar a la formación de praderas artificiales con la cual se podrá aumentar en el futuro, la actual densidad ganadera; 9. Creación de un mercado comprador de lanas con amplia influencia sobre el altiplano"15.

El plan surgió de un convenio establecido por la JAA con la Universidad de Chile y tuvo como principal hito la instalación de la "Estación Zootécnica de Misitune" situada en el altiplano ariqueño. En ella se realizaron estudios comparativos de lana de auquénidos de diversas regiones, experiencias forrajeras, de forestación y aplicación de bases zootécnicas generales.

A 5 años de iniciado el plan, este llegó abruptamente a su término sin lograr los objetivos propuestos.

Contemporáneamente al Plan de Desarrollo Agropecuario y Plan Auquénidos, se desplegaron planes para la superación del Analfabetismo, el Plan para el Mejoramiento de las Condiciones de Vida y el Plan Caminero que aportaron con la implementación de materiales para las escuelas, construcción de casas para postas sanitarias y mejoramiento del alumbrado público para casi la mayoría de los poblados precordilleranos y pueblos centrales altiplánicos.

\footnotetext{
${ }^{14}$ Quiroz, Diego, Díaz, Alberto, Galdames Luis, y Ruz, Rodrigo. 2011. “Campesinos andinos y políticas agrarias durante la Junta de Adelanto de Arica (Azapa, Lluta y la precordillera (1959-1976)", en IDESIA (Chile), Vol. 29, № 2, Arica, pp. 157-168.

${ }^{15}$ AHVD. Estación Misitune, 1965. Estudios Técnicos JAA.
} 
La implementación a los poblados rurales de servicios y equipamiento urbano, buscaba sobre la base de la conexión caminera especialmente, integrar y superar el aislamiento de centros agrícolas y potencialmente mineros, así como dotar de una proyección turística, aspectos esbozados, pero paradójicamente ausentes en planes formales ${ }^{16}$. En este contexto se construyeron los principales tramos que unen los pueblos importantes de la precordillera: tramo Parinacota-Caquena; Ticnamar-Belén-Putre-Socoroma-Zapahuira y el camino agrícola del valle de Codpa.

La importante actividad e inversión realizada en los sectores rurales del departamento, así como la visibilidad que adquirió la población indígena regional en las esferas políticas, llevaron a que el año 1960 la JAA solicitara al "Programa Andino" el estudio y aplicación de programa que macrorregionalemente se venían implementando en países andinos con una alta presencia indígena.

El Programa Andino propiciado por la Organización Internacional del Trabajo (OIT) perseguía la promoción del desarrollo campesino andino en América Latina, instancia que, como hemos indicado con anterioridad, se encontraba inspirada en la idea del desarrollismo clásico, basando su convicción en que la pobreza podría resolverse con inversiones adecuadas en capital físico e infraestructura. La teoría de la modernización percibía el desarrollo como crecimiento económico, implicando un mejoramiento de las condiciones de vida de sociedades tradicionales, diseñadas bajo criterios capitalistas de racionalización productiva y mayor aumento de capacidades de ingreso ${ }^{17}$.

El Programa Andino tuvo sus primeras expresiones en Ecuador, Bolivia y Perú, escaló a Argentina, y en el período que se presenta llegó al Norte Grande chileno. El programa en sus distintos escenarios y momentos estuvo atravesado en los países donde fue aplicado, coexistió con la política contingente; a saber: políticas reformistas en el agro, colonización de espacios rurales, innovación agraria y descentralización. Los casos documentados en el Perú y Ecuador principalmente dan cuenta que la experimentación de las ideas de integración y desarrollo (Perú y Bolivia) bajo el marco teórico del funcionalismo imperante en la antropología de la época; mientras que en Ecuador el enfoque estuvo orientado hacia una política de acceso a los hogares rurales y perspectiva de género ${ }^{18}$.

\footnotetext{
${ }^{16}$ Torrent, Horacio y Ruz, Rodrigo."2020. Proyectos para el desarrollo de Arica y su región en los años sesenta”, en Diálogo Andino, Arica. (Artículo aceptado).

17 Degregori Carlos y Huber, Ludwing. 2005. “Cultura, poder, y desarrollo rural”, en Iguíñez, Javier, Escobal, Javier y Degregori, Carlos. Perú el problema agrario en debate. Sepia IX Seminario permanente de investigación agraria, Lima, Sepia.

18 Prieto, Mercedes. 2016.El programa indigenista andino, 1951-1973. Las mujeres en los ensambles estatales del desarrollo, Lima/ Quito, Instituto de Estudios Peruanos/ FLACSO.
} 
El nexo chileno con el Programa Andino tuvo su gestación el año 1960, momento en que la ya activa, la JAA solicita al programa se estudiaran las condiciones de vida de la población indígena regional, ya bajo el paradigma desarrollista andando ${ }^{19}$.

La JAA tomando como base la experiencia del Programa Andino desarrolla una estrategia para el desarrollo rural creando el Departamento de Desarrollo Comunitario y el Plan Andino el año 1962, el cual funciona hasta el año 1965.

El diagnóstico desarrollado por el Programa Andino sugirió el despliegue de aspectos no solamente productivos y sectoriales, sino que dirigidos al crecimiento económico junto al desarrollo de la comunidad ${ }^{20}$.

El trabajo conjunto entre ambos, Plan de Desarrollo Comunitario y el Plan Andino, en sintonía con las experiencias internacionales, y bajo la supervisión de representantes de la Organización de las Naciones Unidas para la Alimentación y la Agricultura (FAO) y Organización de las Naciones Unidas para la Educación, la Ciencia y la Cultura (UNESCO), determinaron que los principales problemas que se encontraban de las comunidades andinas del Departamento de Arica estaban en: "1. Las condiciones [malas] de salubridad de los pueblos, 2. Mejorar el rendimiento de los predios agrícolas y 3. Capacitación de funcionarios públicos y maestros rurales" ${ }^{21}$.

El programa del Plan Andino, definió una estrategia centrada en los aspectos educacionales de la población. Para ello contaba con una base importante en las estrategias regionales desplegadas por el Estado chileno quien junto a la JAA designa a un experto de la UNESCO en Educación Rural para extender sus políticas centradas en el robustecimiento de la educación rural, tornando a la escuela como eje de la vida en comunidad, considerando que la escuela hacia entrada la década de 1960 contaba con un tejido social vinculado. Adicionalmente se observaba que las denominadas "Juntas de Vecinos" eran potencialmente otro aliado en el: "desarrollo de actividades en favor del mejoramiento de las condiciones de vida en comunidad"22. El Plan Andino, por medio de la escuela y la actividad vecinal, promovió: "el desarrollo de sentimientos sociales. La libre asociación, conciencia de grupo, espíritu de servicio y colaboración. Interesando a los vecinos a favor de la labor educativa para elevar el nivel cultural, económico y social de la población andina"23.

\footnotetext{
${ }^{19}$ Galdames, Luis.2005. "El discurso del Estado a través de la creación del Puerto Libre de Arica: Aproximación semiológica", Diálogo Andino, №26, Arica, pp. 9-14; Ruz, Rodrigo y Galdames, Luis.2010. "La Junta de Adelanto de Arica y John V. Murra: Dos lecturas sobre el desarrollo andino en el norte de Chile", Chungara: Revista de antropología chilena, Vol. 42, №1, Arica, pp. 257-270.

${ }^{20}$ Mercedes Prieto, El programa indigenista andino, 1951-1973.

21 Programa Andino. Proyecto Arica. Informe 3, abril, junio de 1963.

22 Ídem.

23 Ídem.
} 
Los planes de acción programáticos del Plan Andino consideraban la capacitación a dirigentes y funcionarios públicos que desarrollaban su quehacer en el espacio rural. Los contenidos y materias abordadas en sus propuestas circularon en desarrollar conocimiento en asistencia en salud, desarrollo de actividades agropecuarias en cultivos, crianza de animales y conceptos sobre características del subdesarrollo y organización de la comunidad.

El Plan Andino poseía la particularidad que los funcionarios que desarrollaban estas capacitaciones eran funcionarios que venían realizando su labor en los espacios altiplánicos y precordilleranos, o bien vecinos representativos y con experiencia migratoria urbana conocedores de los procesos supuestamente virtuosos que el modelo urbano tenía.

Estos funcionarios "intermediarios" entre el Plan y las comunidades Andinas, fueron adquiriendo formalidad a partir de la implementación del "Comité de Coordinación y Planeamiento" que tenía:

"las funciones de estudiar los problemas que afectan a la comunidad, buscando las soluciones adecuadas de acuerdo con las necesidades de la comunidad, promoviendo el funcionamiento y organización de la Junta de Vecinos, siendo con ellos con quienes elaboran los planes de trabajo. Estos comités estaban conformados por los subdelegados, juez de Subdelegación, jefe de retén de carabineros, Oficial Civil y el director junto a los profesores de las escuelas rurales" 24 .

Es reconocida la labor del Plan Andino, en cuanto sus esfuerzos y avances en materia de establecer nexos con comunidades, su labor educativa en función de los objetivos de las entidades mandantes, también la canalización de obras provenientes de la inversión de la JAA. No obstante, entrando la segunda mitad de la década de 1960, comienzan a aparecer las críticas al giro asistencialista que adquirió el plan en cuanto este se alejó de los iniciales esfuerzos en inversión en infraestructura esbozados por los planes y programas de la Junta.

Las críticas representadas en la voz de uno de los consejeros de la JAA y futuro alcalde de la ciudad de Arica, Santiago Arata Gandolfo, reflejaban el sentir de las autoridades del período:

"la labor del Plan [Andino] se está desarrollando pero con el dinero de la Junta, el Desarrollo Comunitario no ha hecho nada, me consta a mí y al señor Guerra, el Plan Andino ha sido el gran ausente, sin embargo se han encontrado con una obra que en el diario figura hecha por ellos, en circunstancias que no es efectivo, y la iniciativa ha sido de los pobladores, de los profesores rectores en ese pueblo y de la JAA en el aspecto material" 25 .

Terminada la década el Plan Andino se había convertido en un programa asistencialista en lo social y técnico, situación en la que lo encontró el comienzo de la década de 1970 y el golpe

\footnotetext{
24 Ídem.

${ }^{25}$ AHVD. Acta 310. 1964. Estudios Técnicos JAA.
} 
de estado de Augusto Pinochet, que aparentemente no renovó los enfoques ni la inversión, aspecto retomado iniciada la década de 1990 a través de la creación de organismos específicos como la Comisión Especial de Pueblos Indígenas, CEPI (1990) que dio paso a la creación del organismo estatal que aborda problemáticas indígenas: Corporación Nacional de Desarrollo Indígena, CONADI (1993).

En el plano económico, no es del todo claro que, entrada la década de 1960, la JAA tuviera una adecuada ejecución de los Planes de Inversiones contemplados para sus sectores rurales y que fueran congruentes con los diseños globales, que - recordemos- estaban asentados en el papel de la ciudad de Arica como núcleo de desarrollo. A pesar de esta indefinición, resulta irrefutable una programación de una inversión por asentar en ejes estratégicos definidos en las comunidades rurales.

\section{Hacia el "desarrollo del interior", el (aún) indefinido papel del sector agropecuario, y la fallida inclusión de variables culturales en la programación, 1965-1976}

Finalizando la década de 1960, la JAA era la única corporación regional autónoma preexistente a la introducción de la política nacional de desarrollo regional a nivel nacional, situación que toma relevancia finalizando la década. El año 1968 la JAA recurre a la asesoría de la recientemente creada Oficina de Planificación, ODEPLAN, para la formulación de una estrategia de desarrollo orientada hacia las actividades generadoras de empleo, así como de nuevos ingresos para la propia JAA, para hacer sustentable su operación regional considerando los espacios interiores ${ }^{26}$.

Los problemas diagnósticos identificados por la gestión de la JAA y todos los planes y programas sectoriales aparecieron como insuficientes para sostener el modelo que presentaba a la ciudad de Arica como puntal del desarrollo. El interior y las comunidades, a pesar de la inversión, se transformaban en un problema irresuelto a los ejes productivos que debían sostener el crecimiento regional: industria, comercio e incipientemente el turismo.

Ya hacia 1968, en pleno proceso de diseño de estrategias de desarrollo regional elaboradas por el Instituto de Economía de la Universidad de Chile, con miras a ser implementadas por ODEPLAN, señalaban la necesidad de extender o robustecer los programas modernizadores de los sectores interiores, considerado al interior como una "micro región". ${ }^{27}$

Con la teoría de los polos de desarrollo puesta como paradigma, la experiencia del Departamento de Arica en cuanto medidas y políticas sectoriales y su inversión desde la década de 1950 era relevante en cuanto el modelo exigía la concentración de centros que teóricamente

\footnotetext{
${ }^{26}$ Torrent, Horacio y Ruz, Rodrigo "Proyectos para el desarrollo de Arica y su región en los años sesenta". 27 Ídem.
} 
erosionan la economía de las áreas circundantes; difundiendo sobre las mismas el resultado del crecimiento en el centro ${ }^{28}$.

En 1968 se inicia un proceso inconcluso de planificación proyectado al alero de la implementación de polos de desarrollo. A partir del estudio preinversional elaborado por la Universidad de Chile se propone:

"el reemplazo de la economía de subsistencia por una que signifique mejorar las condiciones de vida e ingresos de la población del interior; crear nuevas fuentes de trabajo; fortalecer las comunidades de la pre-cordillera y del altiplano en lugares tales que signifiquen escalones de subida y bajada para la población proveniente del altiplano; dotar de equipamiento básico a esas comunidades para facilitar el arraigamiento de sus pobladores; y otorgar representatividad a dichas comunidades en organismos como la JAA y la Municipalidad". ${ }^{29}$

El estudio de preinversión volvía a destacar aspectos diagnósticos que podrían definirse como estructurales en cuanto la oposición de un mundo tradicional versus un mundo moderno a nivel económico, social y cultural. En este, se reiteraba el escenario en donde el monopolio urbano ariqueño demostraba el relativo éxito de la modernización, ya que evidenciaba a la fecha un estilo de vida moderno, desarrollo industrial y comercial en oposición a las prácticas culturales tradicionales indígenas, que a pesar de los esfuerzos desplegados en cuanto a inversión sectorial con miras a modernizar sus prácticas productivas y tecnológicas, propendiendo a que las personas se mantuvieran en sus pueblos de origen, no se reflejaba como un resultado esperado. La migración y despoblamiento del territorio andino, era un hecho. El gráfico 1, por un lado, evidencia que la ciudad de Arica tuvo un crecimiento absoluto entre 1907 y 1966, desde 11000 a 90000 habitantes, con una sola interrupción de dicha tendencia entre 1940 y 1943 y, por el otro, que en términos de tasas de crecimiento porcentual demográfico se aprecian "ciclos" de crecimiento/contracción demográfica en donde las tasas de expansión con posterioridad a 1952 son realmente explosivos, en comparación al 52,2\% registrado en 1920, superando el 70\%. Los gráficos 2 y 3 muestran, además, una gran concentración de la población en Arica tanto en términos absolutos como porcentuales en desmedro de las áreas del interior del departamento (véase también la figura, para geograficar mejor lo aseverado acá); sumado, además, al despoblamiento de las comunas subdelegación dentro del departamento en cuestión, al sumarlas, pasando de 10634 en 1952 a 8237 personas en 1970.

\footnotetext{
28 Ídem.

29 Duhart, Emilio y H. Suarez. 1968. Arica. Estudio pre-inversional, Ministerio de Vivienda y Urbanismo, Corporación de Mejoramiento Urbano, Santiago, DUR, 1968, citado en Torrent, Horacio y Ruz, Rodrigo "Proyectos para el desarrollo de Arica y su región en los años sesenta: El turismo en el laboratorio de los polos de crecimiento y la identidad del espacio andino".
} 


\section{Gráfico 1}

Crecimiento demográfico absoluto y porcentual de la ciudad de Arica, 1907-1966

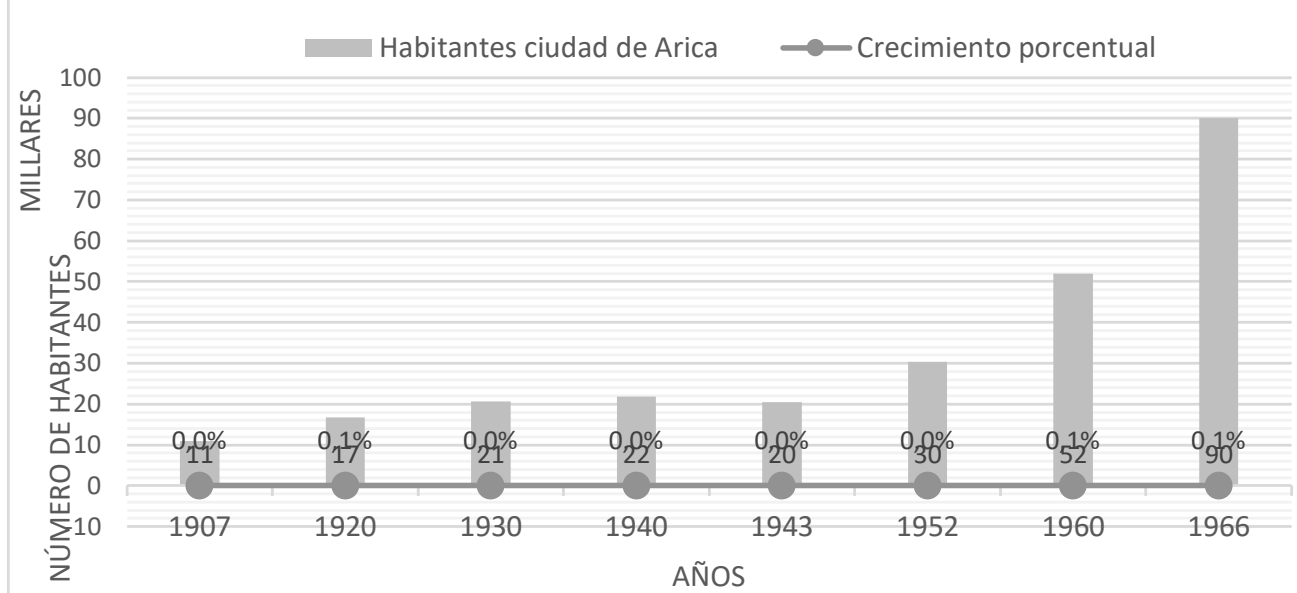

Fuente: elaboración propia sobre la base de los Censos demográficos de 1952, 1960, 1970 y Wormald (1976).

\section{Gráfico 2}

Distribución geográfica de la población por Comuna Subdelegación del altiplano, sierra y valles, 1952, 1960, y 1970

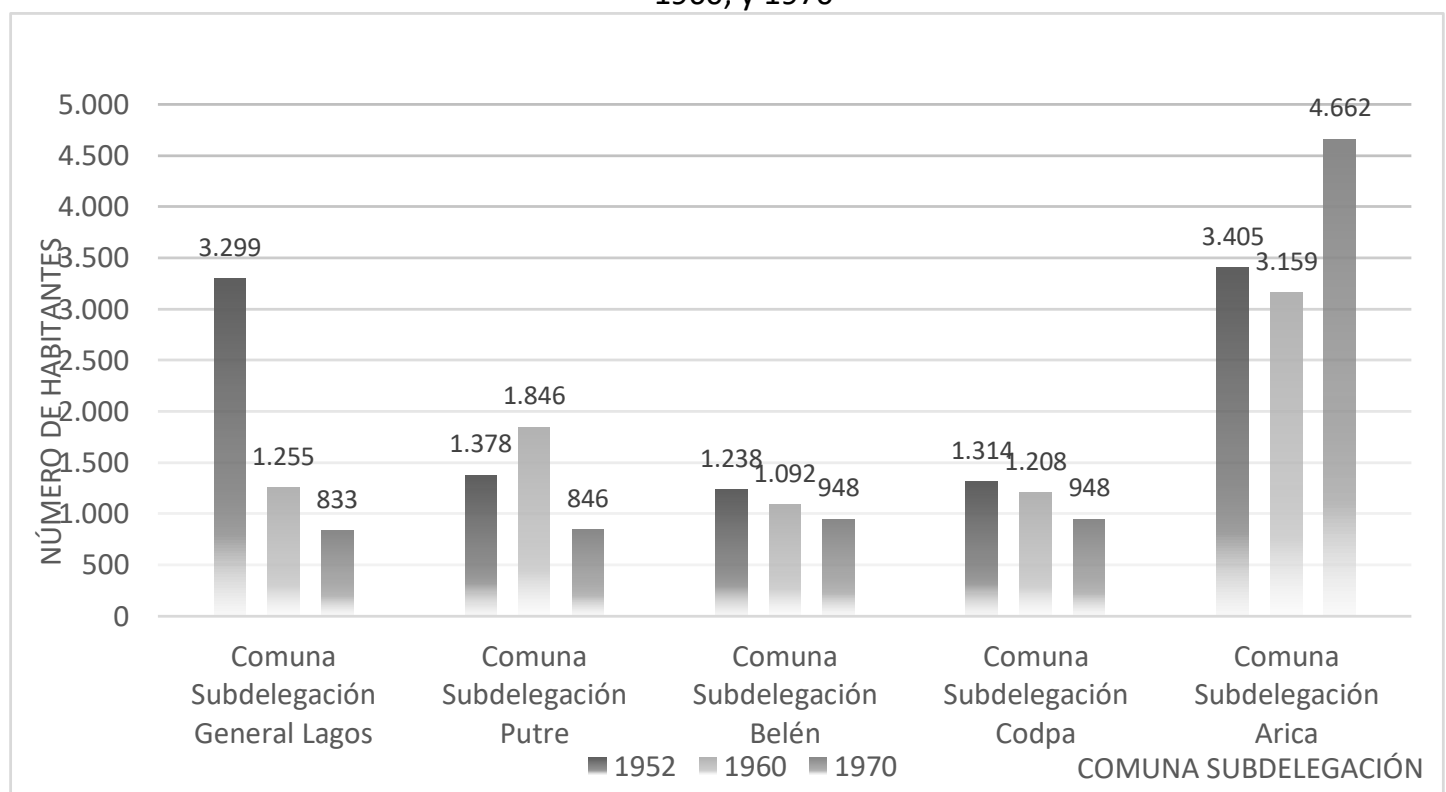

Fuente: elaboración propia sobre la base de los Censos demográficos de 1952, 1960, y 1970. 


\section{Gráfico 3}

Distribución geográfica porcentual de la población por Comuna Subdelegación del altiplano, sierra y valles, 1952, 1960, y 1970

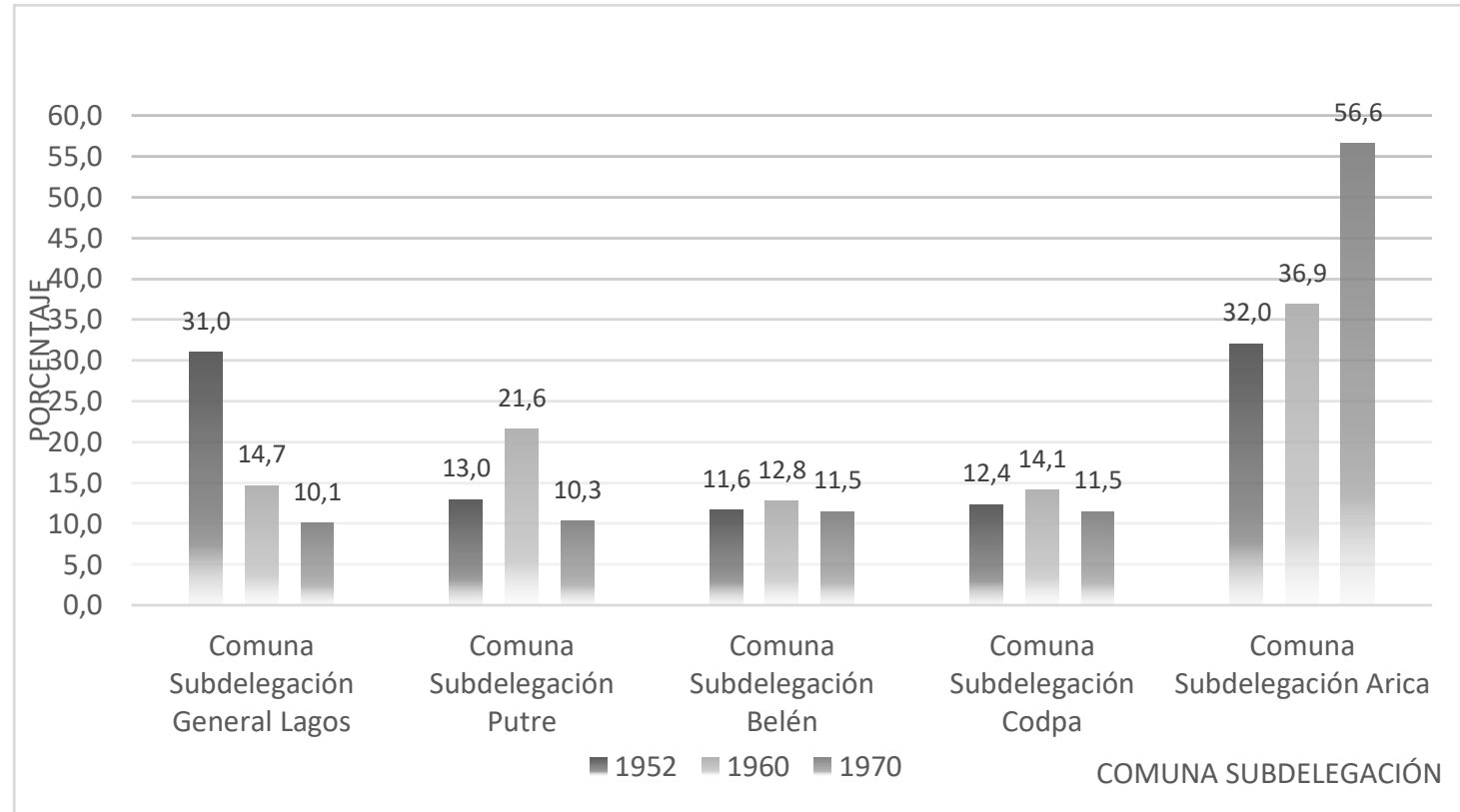

Fuente: elaboración propia sobre la base de los Censos demográficos de 1952, 1960, y 1970.

El estudio preinversional de 1968 identificaba a nivel de jerarquías un centro nuclear urbano (Arica), un segundo núcleo importante en el poblado rural de Putre, dos de mediana jerarquía en Codpa y Poconchile, además de otros de relativa jerarquización en Chapiquiña, un área altiplánica integrada por Visviri, Cosapilla, Caquena y Parinacota (Figura 1). Por tanto, la localización geográfica de sus habitantes estuvo bastante concentrada hacia la costa, principalmente en la comuna de Arica.

Corrido los años sesenta era más o menos claro el peregrino y temprano papel ejercido por la labor de la JAA en cuanto la proyección de la ciudad de Arica como "lugar clave en la estructura territorial local y en la estructuración regional internacional" ${ }^{30}$. En cambio, ello no era claro para los asentamientos rurales los que se presentaban como distanciados de esta dimensión de desarrollo por dos aspectos irresueltos después de casi dos décadas de inversión sectorial. Por un lado, los poblados eran pequeños en tamaño, peso demográfico, aislados y,

\footnotetext{
${ }^{30}$ Boisier, Sergio .1972. Polos de desarrollo: hipótesis y políticas: estudio de Bolivia, Chile, Perú, Ginebra, Instituto de Investigaciones de las Naciones Unidas para el Desarrollo Social, Informe 72.1.
} 
por el otro, seguían sosteniendo prácticas culturales consideradas como premodernas y ajenas al paradigma desarrollista. ${ }^{31}$

Figura 1

Focos urbanos para el interior del Departamento de Arica. Ministerio de Vivienda y Urbanismo, Corporación de Mejoramiento Urbano

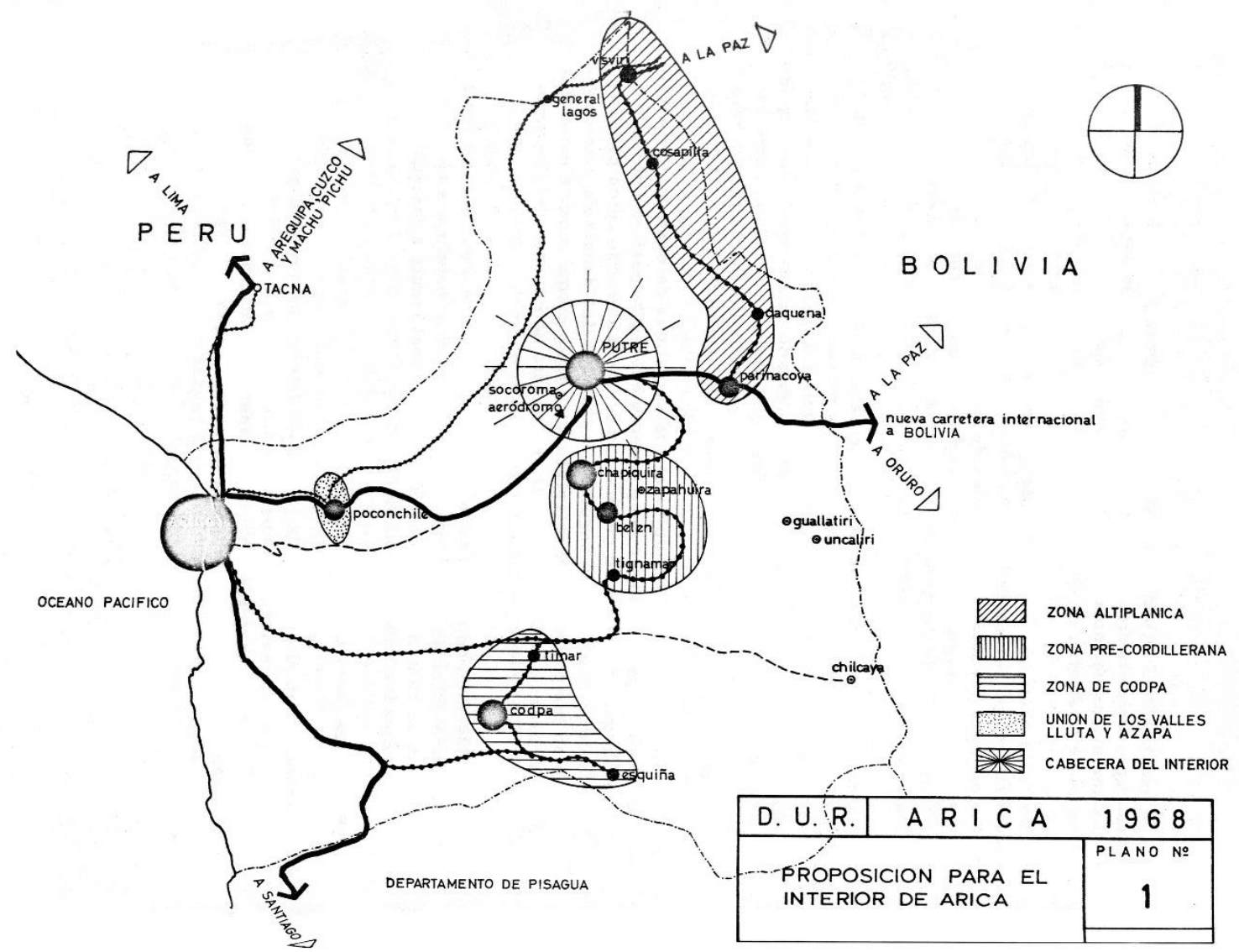

Fuente: Horacio Torrent y Rodrigo Ruz, "Proyectos para el desarrollo de Arica y su región en los años sesenta: El turismo en el laboratorio de los polos de crecimiento y la identidad del espacio andino", Diálogo andino, en prensa.

El estudio preinversional de establecimiento de polos de desarrollo regionales, volvía a otorgar a la JAA la responsabilidad de hacer levantamientos exhaustivos de los equipamientos y servicios existentes en el departamento, seguramente con fin de programar las inversiones necesarias. Terminada la década de 1960 e iniciada la de los setenta, el escenario poblacional en el Departamento de Arica presentaba un indesmentible despoblamiento que sin duda afectó a las planificaciones centrales respecto de la implementación de sus visiones de desarrollo. No

\footnotetext{
31 Luis Galdames y Rodrigo Ruz, "La Junta de Adelanto de Arica y John V. Murra: Dos lecturas sobre el desarrollo andino en el norte de Chile"
} 
obstante, se debe señalar que, a partir del inicio de las planificaciones desarrollistas en la década de 1950, las comunidades venían manifestado una estructura demográfica decreciente, situación explicada por la atracción urbana representada por la ciudad de Arica. No obstante, una mirada en perspectiva indica que un esperado "colapso" demográfico o abandono de los lugares de origen no ocurrió, ni ha ocurrido; sino que las comunidades y personas andinas establecieron movilidades permanentes y bidireccionales hacia los espacios urbanos, situación que a partir del período estudiado se estableció como un patrón ${ }^{32}$. El despoblamiento a partir del período presentado se establece como una nueva y compleja situación estructural de análisis, cuya comprensión depende de lo que ocurre no solo en las comunidades interiores, sino también en sus prolongaciones urbanas que deben ser consideradas.

Entrada la década de 1970, los programas y planificaciones conducentes a insertar en la dinámica del desarrollo a las comunidades andinas departamentales, no estaban del todo bien ponderadas. A las críticas a su enfoque asistencialista evidenciado por las autoridades de la JAA, se suman los cuestionamientos provenientes de espacios académicos que venían estudiando el espacio, sociedad y cultura andina, quienes en intervenciones directas a las autoridades y promotores del modelo exigían la consideración de los valores y cultura andina en las avasalladoras propuestas desarrollistas. Intervenciones de desatacados etnólogos como John Murra ${ }^{33}$ y Vadclav Solc ${ }^{34}$ respecto de la situación, exigían que para asegurar el sostenimiento de planes era menester incorporar la variable cultural al paradigma ${ }^{35}$. Incluso en el ámbito de la economía, el papel del sector agropecuario en el desarrollo del interior fue cuestionado.

\section{Conclusiones provisorias y proyectadas: La década de 1970 y la dictadura en su relación con el espacio andino.}

Previo al Golpe de Estado de 1973, se crea en el departamento el Comité de Desarrollo del Interior (1972), que incorporaba como objetivo: "obtener y recabar un conocimiento cabal de la cultura y los valores de los pueblos que allí habitan, con el fin de hacer más acorde la estrategia de Desarrollo de la JAA a las características socioeconómica de la población rural”36.

Lejos de esto, y ya con el régimen militar instalado en el Gobierno, el Comité retoma viejos diagnósticos y soluciones, esbozadas en su programación de desarrollo definida en 1974, en donde se evidencia una casi nula incidencia de las variables culturales necesarias para un

\footnotetext{
${ }^{32}$ González, Héctor; Gundermann, Hans; Hidalgo, Jorge. 2014.“Comunidad indígena y construcción histórica del espacio entre los aymara del norte de Chile".

${ }^{33}$ AHVD. Visita al Comité del Señor John Murra quien realiza trabajos Antropológicos en la Zona Altiplánica. 1975. Estudios Técnicos JAA.

${ }^{34}$ AHVD. Propuesta Museo Etnológico. Carpeta 262. 1971. Estudios Técnicos JAA.

35 Galdames, Luis y Ruz, Rodrigo.2010. "La Junta de Adelanto de Arica y John V. Murra: Dos lecturas sobre el desarrollo andino en el norte de Chile".

${ }^{36}$ AHVD. Volumen 22. 1972. Estudios Técnicos JAA.
} 
desarrollo sostenido. La programación de 1974 evidencia una naturaleza asimilacionista, sobre la base de establecer 17 necesidades que supuestamente las comunidades rurales requieren del Estado:

"1. Necesidad de darle, a la comunidad, una estructura social (grupal) más definida, funcional y organizada

2. En general, una evidente necesidad de elevar su actual estándar de vida.

3. Necesidad de una educación más de acuerdo con las exigencias del medio.

4. Necesidad de aumentar su productividad para integrarles a la economía regional

5. Necesidad de dotarles de los medios de comunicación adecuados para permitirles la integración progresiva al medio regional y nacional tanto social, como económicamente.

6. Necesidad de asegurarles una cierta regularidad en sus recursos de agua, fuente fundamental de su economía.

7. Necesidad de elevar su estándar tecnológico para aumentar su productividad y estándar de vida.

8. Necesidad de dotarles de los medios adecuados de sanidad y mejoramiento de su dieta alimenticia.

9. Necesidad de descubrir nuevas fuentes de productividad.

10. Necesidad de darles asesoría concreta en materia de mecanización y abonos para incrementar rendimientos agrícolas.

11. Necesidad de asesoría en materia de mejoramiento de su ganadería y explotación ganadera.

12. Necesidad de contar con un cuadro socio demográfico económico de los habitantes de la región.

13. Necesidad de contar con un cuadro claro de las condiciones de habitabilidad de la población.

14. Necesidad de proveerles suficientemente de modo que no sientan la necesidad imperiosa de emigrar.

15. Necesidad de facilitarle los medios que satisfagan sus necesidades de mercadeo y comercialización.

16. Necesidad de asegurarles un mínimo en materia de sana recreación.

17. A todo lo anteriormente enumerado, debemos agregar las necesidades básicas relacionadas con aspectos de interés nacional" ${ }^{37}$.

37 AHVD. Informe esquema para una programación del desarrollo del interior del Departamento de Arica. 1974. Estudios Técnicos JAA. 
El programa, si bien más detallado y con estrategias mejor definidas en extenso, representa una etapa transicional a la solapada y posteriormente explícita visión geopolítica y económica que predominará en el período militar; esto considerando el término de la JAA en 1976 y el carácter residual de las políticas dirigidas al territorio rural indígena, marcadas por un tinte nacionalista y de establecimiento de una nueva, robusta y militarizada frontera internacional chilena con Perú y Bolivia. Si bien la propuesta y estudio oficial emitido en marzo de 1974 por la más alta jefatura administrativa de la región, representa el resultado de discusiones que, como hemos visto, tiene antecedentes en la década del cincuenta, sesenta y setenta, representa una nueva etapa atravesada por ideología que a su tiempo también es pertinente de evaluar, en la que se termina la continuidad dada por la complementariedad de los regímenes excepcionales diseñados ad hoc para la región.

\section{Referencias citadas}

\section{Bibliografía}

Amin, Samir, Giovanni Arrighi, André Gunder Frank e Inmanuel Wallerstein. 1983[1982]. Dinámica de la crisis global, México, Siglo XXI Editores.

Arrighi, Giovanni. 2014 [1994]. El largo siglo XX: Dinero y poder en los orígenes de nuestro tiempo, España, Akal Ediciones.

Bergesen, Albert. 1980. "Cycles of Formal Colonial Rule”, en Hopkins, Terence K. y Wallerstein, Immanuel (eds.), Processes of the World-System, Beverly Hills, Sage, pp. 119-126.

Boisier, Sergio. 1972. Polos de desarrollo: hipótesis y políticas: estudio de Bolivia, Chile, Perú, Informe 72.1, Ginebra, Instituto de Investigaciones de las Naciones Unidas para el Desarrollo Social.

Brenner, Robert. 2009 [1998]. La economía de la turbulencia global, España, Akal Ediciones.

Chase-Dunn, Christopher and Thomas, Hall. 1997. Rise and Demise: Comparing World-Systems, Nueva York, Westview Press.

De Gregori, Carlos y Ludwing, Huber. 2005. Cultura, poder, y desarrollo rural, Lima, Seminario permanente de investigación agraria.

Díaz, Alberto, Ruz, Rodrigo, Galdames, Luis y Tapia, Alejandro. 2012. "El Arica peruano de ayer. Siglo XIX", en Atenea, Número 505, pp. 159-184.

Galdames, Luis. 1978. Notas epistemológicas sobre la Teoría de la Dependencia, Santiago, ILADES.

Galdames, Luis. 2005. "El discurso del Estado a través de la creación del Puerto Libre de Arica: Aproximación semiológica", en Diálogo andino, Número 26, Arica, pp. 9-14.

Galdames, Luis y Ruz, Rodrigo. 2010. "La Junta de Adelanto de Arica y John V. Murra. Dos lecturas sobre el desarrollo andino en el Norte de Chile", en Chungara, Revista de Antropología Chilena, Volumen 42, Número 1, Arica, pp. 257-270. 
Glyn, Andrew. 2012 (2006). Capitalismo desatado. Finanzas, globalización y bienestar, España, Los Libros de la Catarata.

González, Héctor, Gundermann, Hans y Hidalgo, Jorge. 2014. "Comunidad indígena y construcción histórica del espacio entre los aymara del norte de chile", en Chungara, Revista de Antropología Chilena, Volumen 46, № 2, Arica, pp. 233-246.

González, Sergio. 2008. La llave y el candado. El conflicto entre Perú y Chile por Tacna y Arica (1883-1929), Santiago, Ediciones LOM.

Myrdal, Gunnar. 1953. The Political Element in the Development of Economic Theory, London, Routledge \& Kegan Paul.

Myrdal, Gunnar, 1957, Economic Theory and Underdeveloped Regions, London, Gerald Duckworth \& Co.

Mandel, Ernest. 1986 (1980). Las ondas largas del desarrollo capitalista. La interpretación marxista, España, Siglo XXI Editores.

Pérez, Carlota. 2005 (2003). Revoluciones tecnológicas y capital financiero. La dinámica de las grandes burbujas financieras y las épocas de bonanza, México, Siglo XXI Editores.

Pizarro, Elías y Ríos, Waldo. 2005. "Entre franquicias y beneficios: una apuesta del gobierno para el desarrollo regional de Arica (1953)”, en Diálogo Andino, № 25, Arica, pp. 101-111.

Rostow, Walt. 1961. Las etapas del crecimiento económico. Un manifiesto no-comunista, México, Fondo de Cultura Económica.

Prieto, Mercedes. 2016. El programa indigenista andino, 1951-1973. Las mujeres en los ensambles estatales del desarrollo, Lima-Quito, Instituto de Estudios Peruanos-FLACSO.

Quiroz, Diego, Díaz, Alberto, Galdames, Luis y Ruz, Rodrigo. 2011. "Campesinos andinos y políticas agrarias durante la Junta de Adelanto de Arica (Azapa, Lluta y la precordillera (1959-1976)", en IDESIA (Chile), Vol. 29, Número 2, Arica, pp. 157-168.

Torrent, Horacio y Ruz, Rodrigo. 2020. "Proyectos para el desarrollo de Arica y su región en los años sesenta: El turismo en el laboratorio de los polos de crecimiento y la identidad del espacio andino", en Diálogo Andino (aceptado), Arica.

Wallerstein, Immanuel. 1984. "Long Waves as Capitalist Process", en Review (Fernand Braudel Center), Vol. VII, N 4, Binghamton, pp. 559-575.

Wormald, Alfredo. 1976. "El mestizo en el Departamento de Arica”, Santiago-Chile, Ediciones Ráfaga.

\section{Fuentes Primarias:}

AHVD: Archivo Histórico Vicente Dagnino.

AHVD. 1965. Estación Misitune, Estudios Técnicos JAA.

AHVD. 1964. Acta 310. Estudios Técnicos JAA.

AHVD. 1971. Propuesta Museo Etnológico. Carpeta 262. Estudios Técnicos JAA.

AHVD. 1972. Volumen 22. Estudios Técnicos JAA.

AHVD. 1974. Informe Esquema de Planificación del Desarrollo Agropecuario de Arica. Estudios Técnicos JAA. 
AHVD. 1975. Visita al Comité del Señor John Murra quien realiza trabajos Antropológicos en la Zona Altiplánica. Estudios Técnicos JAA. 